\title{
GMDD: a database of GMO detection methods
}

\author{
Wei Dong ${ }^{\dagger 1}$, Litao Yang ${ }^{\dagger 1}$, Kailin Shen², Banghyun Kim³ ${ }^{3}$ Gijs A Kleter ${ }^{4}$ \\ Hans JP Marvin ${ }^{4}$, Rong Guo ${ }^{5}$, Wanqi Liang ${ }^{1}$ and Dabing Zhang*1
}

\begin{abstract}
Address: ${ }^{1}$ GMO Detection Laboratory, SJTU-Bor Luh Food Safety Center, Key Laboratory of Microbial Metabolism, Ministry of Education, School of Life Science and Biotechnology, Shanghai Jiao Tong University, 800 Dongchuan Road, Shanghai 200240, PR China, ${ }^{2}$ Shanghai Fisheries University, 334 Jungong Road., Shanghai 200090, PR China, ${ }^{3}$ Korea Food \& Drug Administration, 194 Tongiliro, Eunpyung-gu, Seoul 122-704, South Korea, ${ }^{4}$ RIKILT - Institute of Food Safety, Wageningen University and Research Center, Bornsesteeg 45, NL-6708 PD Wageningen, The Netherlands and ${ }^{5}$ Shanghai University, 149 Yanchang Road., Shanghai 200072, PR China
\end{abstract}

Email: Wei Dong - dong_wei@sjtu.edu.cn; Litao Yang - yylltt@sjtu.edu.cn; Kailin Shen - klshen@stmail.shfu.edu.cn;

Banghyun Kim - yebin@kfda.go.kr; Gijs A Kleter - gijs.kleter@wur.nl; Hans JP Marvin - hans.marvin@wur.nl; Rong Guo - guorong@shu.edu.cn; Wanqi Liang -wql421@yahoo.com.cn; Dabing Zhang* - zhangdb@sjtu.edu.cn

* Corresponding author †Equal contributors

Published: 4 June 2008

BMC Bioinformatics 2008, 9:260 doi:10.1186/147/-2105-9-260
Received: 18 January 2008

Accepted: 4 June 2008

This article is available from: http://www.biomedcentral.com/I47I-2/05/9/260

(c) 2008 Dong et al; licensee BioMed Central Ltd.

This is an Open Access article distributed under the terms of the Creative Commons Attribution License (http://creativecommons.org/licenses/by/2.0), which permits unrestricted use, distribution, and reproduction in any medium, provided the original work is properly cited.

\begin{abstract}
Background: Since more than one hundred events of genetically modified organisms (GMOs) have been developed and approved for commercialization in global area, the GMO analysis methods are essential for the enforcement of GMO labelling regulations. Protein and nucleic acidbased detection techniques have been developed and utilized for GMOs identification and quantification. However, the information for harmonization and standardization of GMO analysis methods at global level is needed.

Results: GMO Detection method Database (GMDD) has collected almost all the previous developed and reported GMOs detection methods, which have been grouped by different strategies (screen-, gene-, construct-, and event-specific), and also provide a user-friendly search service of the detection methods by GMO event name, exogenous gene, or protein information, etc. In this database, users can obtain the sequences of exogenous integration, which will facilitate PCR primers and probes design. Also the information on endogenous genes, certified reference materials, reference molecules, and the validation status of developed methods is included in this database. Furthermore, registered users can also submit new detection methods and sequences to this database, and the newly submitted information will be released soon after being checked.
\end{abstract}

Conclusion: GMDD contains comprehensive information of GMO detection methods. The database will make the GMOs analysis much easier.

\section{Background}

With the development of modern biotechnology, numerous genetically modified organisms (GMOs) have been approved for commercialization. However, GMOs' emergence has caused public debate on the consumers' freedom of choice to purchase GMO-derived products or not.
To protect the consumers' freedom of choice, more than 40 countries have issued GMO labelling regulations, for instance, GM foods must be labelled at the threshold of $0.9 \%$ in European Union (EU), 3\% in Korea, and 5\% in Japan [1-3]. In China, no matter how small the GM content is, 17 types of GM products must be labelled, such as 
maize seeds, maize oil, tomato seeds, ketchup, soybean seeds, soybean oil, rapeseed seeds, and cotton seeds [4].

To make sure the successful enforcement of the GMO labelling, protein and nucleic acid-based detection techniques have been developed, or are in the process of development, such as ELISA, lateral flow strip, PCR, and micro-array etc [5-13]. Among these techniques, PCR is the most popular technique for GMOs analysis because of its versatility (from screening to identification), specificity, high throughput, and efficiency, therefore the PCR detection methods have been developed for many GMOs. The introduced DNA fragments are usually integrated into the genome of GMOs by random transformation events: based on the different amplification fragments of the inserted DNA sequences, PCR detection methods of GMOs are grouped into four types, such as the screen-, gene-, construct-, and event-specific PCR methods [6,7]. Moreover, to overcome the difficulties in obtaining the certified reference materials (CRMs) of GMOs, standard reference molecules are developed and used in PCR detection [14-16]. This is a new research hotspot in the field of GMO detection, and this will greatly facilitate the utilization of PCR detection methods.

Up to now, hundreds of GMOs detection methods have been developed, and their number is increasing more and more rapidly. However, with so many detection methods to choose, an analyst may feel confused. To select the most informative analyses beforehand, it is necessary to establish one public database for GMOs analysis methods, providing update analysis information to the analysts. Even though there are some GMO databases related to GMO safety assessment, including Agbios [17], GMOCompass [18], and Biodiv LMO Database [19], etc (all the databases are available till now, 17th April, 2008), these databases are mainly engaged in collecting the information of GMOs' risk assessment, and relatively little information on GMO detection is included.

Here, we report the development of a new database for GMO detection methods. In this database, we have collected almost all the previous developed GMOs detection methods, thus providing a user-friendly search service for GMOs by event name, gene, and protein information, etc. In particular, we supply sequence information of exogenous inserts, if available, as well as endogenous reference genes, and standard reference materials for GMOs analysis in our database. Furthermore, registered users can submit new GMO detection methods or sequences to this database, which makes this database open.

\section{Construction and content System architecture}

The whole system is developed with PHP5 (using framework for development, including Zend Framework 1.0 and Smarty 2.6), MySQL5 for primer information storage. Besides, NCBI BLAST2, and BioPerl package [20] are also introduced to GMDD to achieve a BLAST function for all the exogenous inserted sequences. WWW Primer 3 [21] is also integrated into GMDD, which will help users with primers' design.

\section{Data collection}

In this GMO detection method database (GMDD), we provide the information on two aspects of each approved GMO event, one is the general information on each transformation event for detection purposes, and the other is its detailed detection method information. The general information of GMO events includes the event name, OECD UI (Organization for Economic Co-operation and Development OECD Unique Identifier), trade name, species, newly introduced traits, exogenous inserts, transformation methods, transformation vectors and developing or licensed company.

In particular, the inserted sequences of GMOs in GMDD have been collected from published research articles, Genbank [22], patents, and producer's petitions to governments, some sequences are assembled by Vector NTI Advance $^{\mathrm{TM}}$ 10.3 Contig Express software [23]. In addition to the sequence information, for other information on the transformation event, references have been cited from the original US petitions, Japanese petitions, Agbios [17], GMO-Compass [18], Biodiv LMO Database [19], and GMO watch report [24], etc.

The GMOs detection method information is grouped into nucleic acid-based method and protein-based method. The nucleic acid-based method information includes primers, probes, amplicon length, figures showing primer pair positions, endogenous reference genes, certified reference materials, standard reference molecules, information on validation status, and reference articles. Currently, most protein-based methods are based on commercialized kits, and that is the reason why GMDD covers both commercial kits as well as non-kits methods. The GMO detection information in GMDD has been mainly collected from published research papers, Community Reference Laboratory for Genetically Modified Food and Feed (CRL-GMFF) validation reports, national standards and international standards, for instance, China and international standardization organization (ISO) standards, etc.

\section{Data quantity}

By mid April 2008, we have collected a total number of 136 GMO events, more than 400 pairs of PCR detection 
primers, 30 protein-based methods, 43 endogenous reference genes from 17 taxa, 91 certified reference materials, 9 standard reference molecules, and more than 44 inserted sequences in GMDD.

\section{Utility and discussion Data retrieval}

The GMO detection method information can be searched directly by full event name and by OECD unique identifier. For methods which can be used for testing more than one GMO event (such as screen-, gene-specific PCR, protein-based methods), users can access them by the methods' own search options. For example, gene-specific PCR methods can be searched by their target gene as well as by primer/probe type. For the exogenous DNA sequences of GMOs, users can obtain the available information via the transformation event name or via the BLAST function as provided by GMDD (Figure 1).

\section{Data listed by transformation event}

The general information and analysis data of each GMO in GMDD are presented in the following five main sections: basic information, insertion elements, nucleic acidbased method, protein-based method, and reference materials (Figure 2, Figure 3, Figure 4 and Figure 5). The basic information on each GMO in GMDD comprises the following data, i.e. event name, OECD Unique Identifier, trade name, species, GM new trait, gene introduction method, transformation vector, developing and/or trad-

\section{Search by Event}

Event

OECD UI

\begin{tabular}{|l|l|}
\hline-- Any-- & v \\
\hline-- Any-- & $\checkmark$ \\
\hline
\end{tabular}

Search for Screen-specific PCR

\begin{tabular}{l|lr|}
\cline { 2 - 3 } Element & -- Alll-- & $\checkmark$ \\
\cline { 2 - 3 } Method Type & --- All--- & $\checkmark$ \\
\hline Probe Type & -- -Alll-- & $\checkmark$ \\
\hline
\end{tabular}
Submit

Search for Gene-specific PCR

\begin{tabular}{l|lr|}
\cline { 2 - 3 } Element & -- Bll--- & $\checkmark$ \\
\cline { 2 - 3 } Method Type & --- All--- & $\checkmark$ \\
\hline Probe Type & --- Bll--- & $\checkmark$ \\
\hline
\end{tabular}
Submit ing company. The information on insertion elements includes a general figure of the inserted elements, the known part of the inserted sequences with sketch maps, and the detailed information on gene elements. With this information, users may design new primers or probes more easily, or confirm their detection results with the provided sequences (Figure 2).

The nucleic acid-based methods include the information of PCR primers, probes, endogenous reference gene, and information on the validation status of the method. PCR analysis information is generally grouped into 4 different PCR strategies, screen-, gene-, construct-, and event-specific. Each group is classified into quantitative and qualitative amplification method including further hybridization on chip. For each gene element, all the relevant screen- and gene-specific PCR primers are listed (the information could be retrieved by clicking "View All Possible Screen Method" or "View All Possible Gene-Specific Method"). Furthermore, there is a list of all known endogenous reference genes by taxon. By clicking on the gene name, users will get a list of primers for this gene (Figure 3).

Protein-based methods (including both kits and non-kits methods) cover both ELISA and lateral flow strip methods, and also the information on the validation status of the methods and whether standards for non-kits methods are provided (Figure 4).

\section{Search for Endogenous Reference Gene}

Gene
Species
Method Type
Probe Type
Submit

\begin{tabular}{|c|c|}
\hline ---A\|ll--- & $v$ \\
\hline ---A\|l|--- & $v$ \\
\hline --A||--- & $v$ \\
\hline ---Âl|--- & $v$ \\
\hline
\end{tabular}

\section{Search Protein-Based Method}

\begin{tabular}{lll|} 
Method Type & ---All--- & $\vee$ \\
Gene & ---All--- & $\vee$ \\
\hline
\end{tabular}

Submit

\section{BLAST In Our Database}

Sequence

Sequence length should be more than $10 \mathrm{bp}$, just ' $A$ ' $T$ ' ' $C$ ' ' $G$ '.

Submit

\section{Figure I}

GMDD search interface. i) Users can search the information by event information, ii) or by detection method information, iii) or search inserted sequences by a BLAST function. 


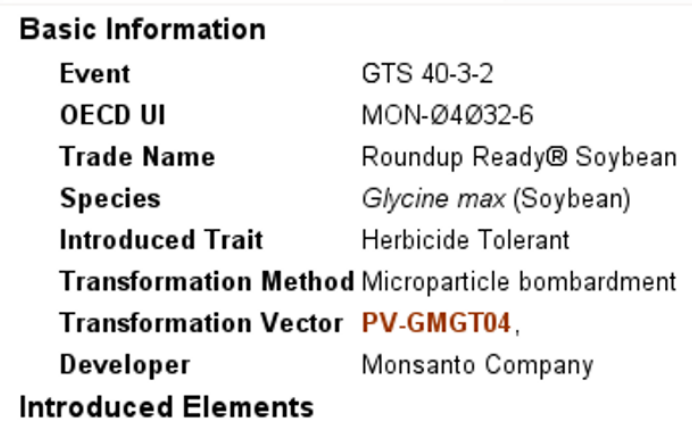

\begin{tabular}{|c|c|c|c|c|c|}
\hline P-35S & CTP4 & CP4 EPSPS & NOS & $\begin{array}{c}\text { CP4 EPSPS } \\
\text { trunc }\end{array}$ & $\begin{array}{c}\text { Recombinant } \\
\text { DNA }\end{array}$ \\
\hline
\end{tabular}

\section{Additional $72 \mathrm{bp}$ CP4 EPSPS fragment}

All Known Sequence:

(1)

\begin{tabular}{|c|c|c|c|c|c|c|c|}
\hline & & & ref: & $\|$ & AJ3085 & $\| \quad A J$ & 515 \\
\hline $\begin{array}{l}\text { Plant } \\
\text { DNA }\end{array}$ & $\begin{array}{c}\text { CaMV } \\
35 \mathrm{~S}\end{array}$ & CTP4 & Cp4 epsps & nos & $\begin{array}{c}\text { Cp4 } \\
\text { epsps } \\
\text { trunc }\end{array}$ & unknown & $\begin{array}{l}\text { Plant } \\
\text { DNA }\end{array}$ \\
\hline
\end{tabular}

+ View Complete Sequence \& Detailed Infomation

I CCCAAGTTCC TAAATCTTCA AGTTITCTTG TITTTGGATC TAAAAACTG

51 AAAAATTCAG AACCTTGTGC AAATTATTCA AACCCTTCAA TTTAACCGAT

101 GCTAATGAGT TATTITIGCA TGCTTTAATT TGTTTCTATC AAATGTTTAT

151 ITTTITTTAC TAGAAATAAC TTATTGCATT TCATTCAAAA TAAGATCATA

201 CATACAGGTT AAAATAAACA TAGGGAACCC AAATGGAAAA GGAAGGTGGC

251 TCCTACAAAT GCCATCATTG CGATAAAGGA AAGGCCATCG TTGAAGATGC

301 CTCTGCCGAC AGTGGTCCCA AAGATGGACC CCCACCCACG AGGAGCATCG

351 IGGAAAAAGA AGACGITCCA ACCACGTCTT CAAAGCAAGT GGATTGATGT

401 GATATCTCCA CTGACGTAAG GGATGACGCA CAATCCCACT ATCCTTCGCA

451 AGACCCTTCC TCTATATAAG GAAGTTCATT TCATITGGAG AGGACACGCT

Target Gene

\begin{tabular}{|c|c|c|}
\hline \multirow{6}{*}{$\begin{array}{l}\text { cp4 epsps } \\
\text { cassette }\end{array}$} & \multirow{2}{*}{ Promtor: } & P-35S-CTP4 \\
\hline & & enhanced CaMV 35S; chloroplast transit peptide from Petunia hybrida \\
\hline & \multirow{2}{*}{ Coding Region : } & Coding 5-enolpyruvylshikimate-3-phosphate synthase \\
\hline & & From Agrobacterium tumefaciens \\
\hline & \multirow{2}{*}{ Terminator: } & NOS 3' \\
\hline & & A. tumefaciens nopaline synthase (nos) 3'-polyadenylation signal \\
\hline
\end{tabular}

Molecular Characterization

As mentioned in the Monsanto's original petition, GTS40-3-2 contains a single insert, containing P-35S, CTP4, cp4 epsps, and T-nos. No other elements are found in the cotton genome.

Additional studies conducted by Monsanto showed that the insert of T-nos is complete. A 250 bp segment of the cp4 epsps, and a 534 bp rearrangement of the DNA are found adjacent to the 3' end of the T-nos. Besides, a 72 bp cp4 epsps inactive fragment is also found in the genome.

\section{Figure 2}

Basic information of GTS 40-3-2. Information is grouped into i) basic information, ii) introduced elements: including general figure, sequences (if the sequence was longer than $500 \mathrm{bp}$, only the first $500 \mathrm{bp}$ would be displayed on this page), gene elements illustration, and molecular characterization. 

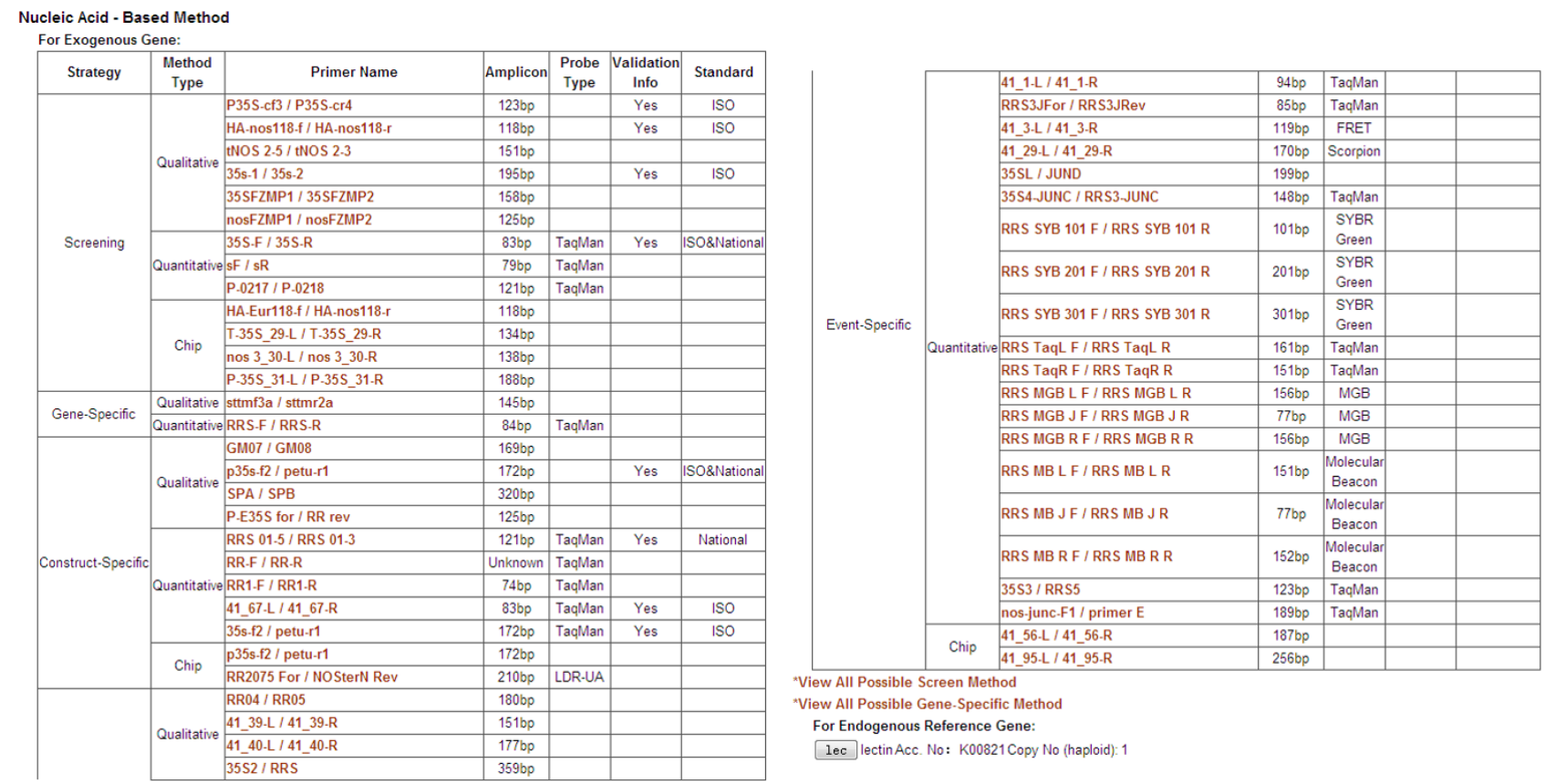

Figure 3

Nucleic acid-based method of GTS 40-3-2. i) Primers information is grouped into 4 different PCR strategies, screen-, gene-specific, construct-specific, and event-specific, ii) Predicted possible primers, iii) Endogenous reference gene, iv) Standard reference molecules.

In the certified reference materials section, users may find out such information as CRM name, catalogue number, composition and measured content with their measurement uncertainty. The information on standard reference molecules is also included in the certified reference materials section. Users can get detailed information by clicking on the name of standard reference molecules (Figure 5).

\section{Detailed method information}

By clicking on the hypertext link of the primers list, users can get access to the detailed method information. Nucleic acid-based methods' information includes the type of analysis (quantitative, qualitative amplification methods including further hybridization on chip), primer/probe type (TaqMan ${ }^{\oplus}$, Molecular Beacon, and FRET, etc), primer/probe name, primer/probe sequence, amplicon length, information on validation status, references, standard information, and data on the source of the information. In addition, there are PCR reaction parameters for some of the validated detection methods. For screen- and gene-specific method, there is also a list of transformation event names validated by research articles. For construct- and event-specific method, there is a figure indicating the primer pairing positions with the inserted elements, according to the information on GMO inserted sequences and primer sequences (Figure 6). Protein-based method information includes method type, method name, a list of transformation event names validated by research articles, references, and data on the source of the information.

\section{Submit new information to GMDD}

GMDD also provides the service for users to submit new detection methods, inserted sequences and to comment or to submit supplementary information for specific methods of detection. This should be helpful for improving the information content in the future and also it will constitute a platform for information exchange between researchers and analysts in the field of GMO detection.

We encourage users to submit validated information, that is, the information should have already been published in scientific research papers. The submitted information can not be obtained by others until our administrators have checked it within about 1-2 weeks. During this period, the submitters can edit the method information, and even after we publish the new method on the website, the submitter still has full access to the methods data.

On the page of the detailed method and sequence information, users can submit supplementary references or 


\section{Protein - Based Method}

\begin{tabular}{|c|c|c|c|c|}
\hline Method Type & Taget Gene & Method Name & Ring Trial & Standard \\
\hline \multirow{2}{*}{ Elisa } & cp4 epsps & $\begin{array}{c}\text { prEN ISO } 21572 \text { Method for RR } \\
\text { soybean }\end{array}$ & Validated & ISO \\
\hline & cp4 epsps & $\begin{array}{l}\text { Elisa for RR soybean } \\
\text { (Monsanto) }\end{array}$ & & \\
\hline \multicolumn{5}{|l|}{ Commercial Kit } \\
\hline Method Type & Taget Gene & Product Name & \multicolumn{2}{|c|}{ Producer } \\
\hline Elisa Kit & cp4 epsps & GMO Soya Test Kit & \multicolumn{2}{|c|}{ Strategic Diagnostics Inc } \\
\hline \multirow{3}{*}{ Strip Kit } & cp 4 epsps & $\begin{array}{c}\text { QuickStix (TM) Strips for } \\
\text { Roundup Ready } \odot \text { in Soybeans }\end{array}$ & \multicolumn{2}{|c|}{ EnviroLogix, Inc. } \\
\hline & cp4 epsps & Agri-Screen CP4 Strip Test & \multicolumn{2}{|c|}{ Neogen Corp. } \\
\hline & cp4 epsps & $\begin{array}{l}\text { Roundup Ready } \\
\text { ImmunoStrip(TM) }\end{array}$ & \multicolumn{2}{|c|}{ Agdia, Inc. } \\
\hline
\end{tabular}

\section{Figure 4}

Protein-based detection methods of GTS 40-3-2. These are classified into reported method and commercial kit.

comments (Figure 6). And if the method can be used in the detection of more than one GM event, users can also add new event names to the database. Except for the users' comments, all the other information will be checked by the administrator.

\section{Conclusion}

With the comprehensive information of nearly all the existing GMO detection methods, including GMO basic information, transformation information and clearly classified detection methods information, and with the new method submission and comment function, GMDD will be a platform for analysts to exchange their data, issues and ideas on GMO detection. This will make the development and validation of new detection methods much easier. It will be more convenient for GMO detection laboratories choosing fit for purposes detection methods.

Because most of the GMO sequences are still unknown to us, and the sequence information contained by the GMDD database is of great importance to the development of new methods, the GMDD consortium plans further to organize a project of sequencing GMO insert border sequences or even the whole inserted sequences, alternatively, initiate the cooperation with the developing

\begin{tabular}{|l|l|c|c|}
\hline \multicolumn{1}{|c|}{ Cat. No. } & \multicolumn{1}{|c|}{ Name } & Average & SD \\
\hline ERM-BF410A & ROUNDUP READY SOYA (blank) & $<0.3 \mathrm{~g} / \mathrm{kg}$ & $\mathrm{g} / \mathrm{kg}$ \\
\hline ERM-BF410B & ROUNDUP READY SOYA (level 1) & $1.0 \mathrm{~g} / \mathrm{kg}$ & $\pm 0.5 \mathrm{~g} / \mathrm{kg}$ \\
\hline ERM-BF410C & ROUNDUP READY SOYA (level 2) & $5.0 \mathrm{~g} / \mathrm{kg}$ & $\pm 1.0 \mathrm{~g} / \mathrm{kg}$ \\
\hline ERM-BF410D & ROUNDUP READY SOYA (level 3) & $10.0 \mathrm{~g} / \mathrm{kg}$ & $\pm 1.6 \mathrm{~g} / \mathrm{kg}$ \\
\hline ERM-BF410E & ROUNDUP READY SOYA (level 4) & $20.0 \mathrm{~g} / \mathrm{kg}$ & $\pm 2.6 \mathrm{~g} / \mathrm{kg}$ \\
\hline ERM-BF410F & ROUNDUP READY SOYA (level 5) & $50.0 \mathrm{~g} / \mathrm{kg}$ & $\pm 5.3 \mathrm{~g} / \mathrm{kg}$ \\
\hline
\end{tabular}

"View All CRMs (The CRMs are provided by IRMM, AOCS, and Sigma)

Reference Molecules: pMuISL2,

\section{Figure 5}

Certified reference materials of GTS 40-3-2. 
Primer Infomation

\begin{tabular}{|c|c|c|c|c|c|c|}
\hline Plant DNA & & & & $35 s$ & & \\
\hline & & & $\begin{array}{l}\vec{F} 1 \\
\text { ofail-R1 } \\
\text { ofail-s2 }\end{array}$ & & & \\
\hline 5 end Junction & & & & & & \\
\hline Mail-F1: TCGAAGGACGAAGGACTCTAA & CGT & & & & & \\
\hline Mail-R1: GCCACCTTCCTITTCCACTATCT & & & & & & \\
\hline Probe Mail-S2: FAM-AACATCCTITGCCA & TTGCCCA & -TAMRA & & & & \\
\hline Validation & & & & & & \\
\hline Item & $<0.02 \%$ & $0.1 \%$ & $0.5 \%$ & $1.00 \%$ & $2.0 \%$ & $5 \%$ \\
\hline Year of the collaborative trial & $2003 / 04$ & $2003 / 04$ & $2003 / 04$ & $2003 / 04$ & $2003 / 04$ & $2003 / 04$ \\
\hline Number of laboratories & 11 & 14 & 14 & 14 & 14 & 14 \\
\hline Number of outliers & 1 & 1 & 0 & 2 & 0 & 0 \\
\hline $\begin{array}{l}\text { Number of laboraories retained after } \\
\text { eliminating outliers }\end{array}$ & 10 & 13 & 14 & 12 & 14 & 14 \\
\hline Mean value $(\%)$ & 0.028 & 0.1023 & 0.4613 & 0.8327 & 1.7814 & 4.5154 \\
\hline Repeatability standard deviation & 0.00736 & 0.03641 & 0.9606 & 0.13744 & 0.28385 & 1.29374 \\
\hline $\begin{array}{l}\text { Repeatability relative standard deviation } \\
(\%)\end{array}$ & 26.27 & 35.60 & 20.82 & 16.51 & 15.93 & 28.65 \\
\hline Repeatability limit & 0.0206 & 0.1019 & 0.269 & 0.3848 & 0.7948 & 3.6225 \\
\hline Reproduibility standard deviation & 0.02326 & 0.04646 & 0.20068 & 0.26534 & 0.56609 & 1.65451 \\
\hline $\begin{array}{l}\text { Reproducibility relative standard deviation } \\
(\%)\end{array}$ & 83.03 & 45.43 & 43.5 & 31.86 & 31.78 & 36.64 \\
\hline Reproducibility limit R & 0.0651 & 0.1301 & 0.5619 & 0.743 & 1.5851 & 4.6326 \\
\hline
\end{tabular}

\section{Submitter}

TFmao

Shanghai Jiaotong University, China

E-mail: zhangdb@sjtu.edu.cn

\section{Reference+Add New Reference}

POF 1 . Foodstuffs - Methods of analysis for the detection of genetically modified organisms and derived products - quantitative nucleic acid based methods, prEN ISO 21570

\section{Comment+Add Comments}

\section{Figure 6}

Detailed information of GMOs analysis method. i) Target event information, ii) primer/probe information and a figure indicating the position where primers pair with the exogenous elements, iii) validation information, iv) submitter information, v) reference and comment, registered users can add references and comments by clicking on the hypertext link.

and licensed companies for retrieving more sequence information.

The GMDD consortium will also continue its cooperation with its European partner, RIKILT - Institute of Food Safety (part of Wageningen University and Research Center), by setting up a supplementary database. This joint database will particularly focus on the risk assessments that have been carried out for food and feed use of the transgenic events described by GMDD. The data thus provided by GMDD will constitute a unique combination of sequence data, detection methods, and safety data, thereby providing a useful tool for analytical method developers, regulatory officials from both industry and governments, risk assessors, risk managers, and other interested parties.

\section{Availability and Requirements}

Home page: GMDD can be accessed at [25]

Operating systems: platform-independent 
Programming language: PHP, Perl

License: Academic Free License (AFL) v. 3.0

\section{Abbreviations}

CRL-GMFF: Community Reference Laboratory for Genetically Modified Food and Feed; CRM: Certified Reference Material; FRET: Fluorescence Resonance Energy Transfer; GMDD: GMO Detection method Database; GMO: Genetically Modified Organism; ISO: International Standardization Organization; LMO: Living Modified Organism; OECD UI: Organization for Economic Co-operation and Development (OECD) Unique Identifier

\section{Competing interests}

All authors are professionals employed by Shanghai Jiao Tong University, Shanghai Fisheries University, Korea Food \& Drug Administration, RIKILT - Institute of Food Safety, and Shanghai University, and as such do not have any interests that may conflict with the contents of the article above.

\section{Authors' contributions}

Designing of the database: DZ, LY, WL and WD. Data collection: WD, BK (responsible for data related to Korea), GAK (responsible for data related to Europe), HJPM (responsible for data related to Europe) and LY. Data proofreading: KS. The whole programming work and web server maintenance: WDSoftware testing: RG. All authors have read and approved the final manuscript.

\section{Acknowledgements}

This work was supported by the National Key Basic Research Developments Program of the Ministry of Science and Technology, P. R. China (2007CB 10920I), the National Natural Science Foundation of China (30725022,30700499), the national high-tech project "863" (2006AA I0Z443, 2007AA I 0Z4 I8), the Ministry of Science and Technology P. R. China (2006DFA32820), Shanghai Municipal Committee of Science and Technology (05DZ05003, 06DZ22908), the Science and Technology program of Shanghai Agricultural committee (No. 10-2, 2006) and Shanghai Leading Academic Discipline Project (B205). And also thanks for financial contributions of RIKILT Institute of Food Safety.

We greatly thank X.C. Huang for designing the logo of GMDD, D.Q. Wei for providing us an office to do the web development and testing work, Ms E.J. Kok for her valuable comments to the manuscript, as well as her, H.B. Zhang, L.X. Jiang, X. Li, H.A. Kuiper and D. Becu for their recommendations for the design of the database.

\section{References}

I. European Commission Regulation (EC) 1829/2003 and 1830/ 2003. OffJ Eur Communities 2003, L268: I-28.

2. Notification 2000-31. Ministry of Agriculture and Forestry of Korea 2000.

3. Notification 1775. Food and Marketing Bureau, Ministry of Agriculture, Forestry and Fisheries of Japan 2000.

4. Order 10. Ministry of Agriculture of the People's Republic of China 2002

5. Elenis DS, Kalogianni DP, Glynou K, loannou PC, Christopoulos TK: Advances in molecular techniques for the detection and quantification of genetically modified organisms. Anal Bioanal Chem in press.

6. Miraglia M, Berdal KG, Brera C, Corbisier P, Holst-Jensen A, Kok EJ, Marvin HJ, Schimmel H, Rentsch J, van Rie JP, Zagon J: Detection and traceability of genetically modified organisms in the food production chain. Food Chem Toxicol 2004, 42(7): I I 57- I I 80.

7. Holst-Jensen A, Rønning SB, Løvseth A, Berdal KG: PCR technology for screening and quantification of genetically modified organisms (GMOs). Anal Bioanal Chem 2003, 375(8):985-993.

8. Ahmed FE: Detection of genetically modified organisms in foods. Trends Biotechnol 2002, 20(5):215-223.

9. Yang L, Guo J, Zhang H, Liu J, Zhang D: Qualitative and quantitative event-specific PCR detection methods for oxy-235 canola based on the 3' integration flanking sequence. J Agric Food Chem 2008, 56(6): 1804-1809.

10. Nesvold H, Kristoffersen AB, Holst-Jensen A, Berdal KG: Design of a DNA chip for detection of unknown genetically modified organisms (GMOs). Bioinformatics 2005, 2 I(9):1917-1926.

II. Rudi K, Rud I, Holck A: A novel multiplex quantitative DNA array based PCR (MQDA-PCR) for quantification of transgenic maize in food and feed. Nucleic Acids Res 2003, 3 I ( I I ):e62.

12. Xu J, Zhu S, Miao H, Huang W, Qiu M, Huang Y, Fu X, Li Y: Eventspecific detection of seven genetically modified soybean and maizes using multiplex-PCR coupled with oligonucleotide microarray. J Agric Food Chem 2007, 55(14):5575-5579.

13. Bulcke M Van den, De Schrijver A, De Bernardi D, Devos Y, MbongoMbella G, Casi AL, Moens W, Sneyers M: Detection of genetically modified plant products by protein strip testing: an evaluation of real-life samples. Euro Food Res Technol 2007, 225(I):49-57

14. Yang L, Guo J, Pan A, Zhang H, Zhang K, Wang Z, Zhang D: Eventspecific quantitative detection of nine genetically modified maizes using one novel standard reference molecule. J Agric Food Chem 2007, 55(I): I5-24.

15. Lee SH, Min DM, Kim JK: Qualitative and quantitative polymerase chain reaction analysis for genetically modified maize MON863. J Agric Food Chem 2006, 54(4): I I 24- I I 29.

16. Yang L, Pan A, Zhang K, Yin C, Qian B, Chen J, Huang C, Zhang D: Qualitative and quantitative PCR methods for event-specific detection of genetically modified cotton MonI445 and Mon53 I. Transgenic Res 2005, 14(6):817-83I.

17. Agbios [http://www.agbios.com]

18. GMO-Compass [http://www.gmo-compass.org]

19. Biodiv LMO Database [http://bch.cbd.int/database/organisms/]

20. Stajich JE, Block D, Boulez K, Brenner SE, Chervitz SA, Dagdigian C Fuellen G, Gilbert JG, Korf I, Lapp H: The Bioperl toolkit: Perl modules for the life sciences. Genome Res 2002, I2(10): |6| I-1618.

21. Rozen S, Skaletsky H: Primer3 on the WWW for general users and for biologist programmers. Methods Mol Biol 2000, 132:365-386.

22. Benson DA, Karsch-Mizrachi I, Lipman DJ, Ostell J, Wheeler DL: GenBank. Nucleic Acids Res 2008, 36(suppl_I):D25-30.

23. Wessner DR: Techview software. Planning plasmids. Science 1999, 286: 1495-1496.

24. GMO watch report [http://www.bats.ch/gmo-watch/]

25. GMDD [http://gmdd.shgmo.org]

Publish with Bio Med Central and every scientist can read your work free of charge

"BioMed Central will be the most significant development for disseminating the results of biomedical research in our lifetime."

Sir Paul Nurse, Cancer Research UK

Your research papers will be:

- available free of charge to the entire biomedical community

- peer reviewed and published immediately upon acceptance

- cited in PubMed and archived on PubMed Central

- yours - you keep the copyright 